\title{
Situación del derecho a la maternidad de las mujeres con discapacidad mental en Argentina
}

\author{
Isaac Marcelo Basaure Miranda* \\ Enviado:27 de Junio \\ Dictaminado: 24 de Agosto
}

\section{Resumen}

Este artículo analiza la situación del derecho a la maternidad de las mujeres con discapacidad mental en Argentina. Al mismo tiempo, repasa la jurisprudencia más reciente al respecto, para finalmente determinar si, el Estado argentino, está cumpliendo con las obligaciones asumidas en los tratados internacionales respecto a asegurar tal derecho.

Palabras clave: Maternidad, Discapacidad, Convención sobre los Derechos de las Personas con Discapacidad, Corte Suprema de Argentina.

\section{Situation of the right to maternity of women with mental disabilities in Argentina.}

\begin{abstract}
This article analyzes the situation of the right to maternity of women with mental disabilities in Argentina. At the same time, it reviews the most recent jurisprudence in this regard, in order to finally determine whether the Argentine State is complying with the obligations assumed in international treaties with respect to ensuring such a right.

Key words: Maternity, Disability, Convention on the Rights of Persons with Disabilities, Supreme Court of Argentina.

\section{Sumario}

I. Introducción; II. La igualdad ante la ley: principal motivo de preocupación para la ONU; III. Postura jurisprudencial de la Corte Suprema de Justicia de la Nación: el fallo “I., J. M.
\end{abstract}

\footnotetext{
* Abogado y Procurador por la Universidad Nacional de Lomas de Zamora (Buenos Aires, Argentina). isaacbasaure@gmail.com
} 
s/protección especial"; 3.1 Antecedentes del fallo de la CSJN; 3.2 Sentencia del Juzgado de Primera Instancia; 3.3 Rechazo al recurso de apelación por parte de la Cámara Nacional de Apelaciones en lo Civil; 3. 4 Sentencia de la CSJN; 3.5. El interés superior del niño; 3.6 El fallo "G., M.G, s/protección de persona” y su valioso aporte para interpretar el interés superior del niño; IV. Cuando la gravedad de la discapacidad mental impide el ejercicio del derecho a la maternidad; V. Conclusión; Bibliografía

\section{Introducción}

Teniendo como marco normativo a la Constitución Nacional (en adelante CN) y a los tratados internacionales, el presente trabajo se propone analizar la situación del derecho a la maternidad de las mujeres con discapacidad mental en la República Argentina. En este contexto, se determinará si, el país en cuestión, está cumpliendo con las obligaciones internacionalmente asumidas. De igual modo, estudiaremos la jurisprudencia nacional más reciente al respecto.

El día 28 de mayo de 2008, Argentina, a través del Senado y la Cámara de Diputados de la Nación, reunidos en Congreso, sancionó la ley $26.378^{1}$ por medio de la cual aprobó y ratificó, tanto la Convención sobre los Derechos de las Personas con Discapacidad ${ }^{2}$ (en adelante CRDP), como su Protocolo Facultativo ${ }^{3}$; ambos instrumentos fueron aprobados por la Asamblea General de las Naciones Unidas ${ }^{4}$.

Adecuándonos a la sistemática constitucional que nos ocupa, la ratificación

1 Congreso de la Nación, 2008, Ley 26.378, Buenos Aires, Argentina, 21 de mayo. Disponible en http:// servicios.infoleg.gob.ar/infolegInternet/anexos/140000-144999/141317/norma.htm Consulta: 24 de junio de 2017.

2 Organización de Naciones Unidas (ONU), 2006, Convención sobre los Derechos de las Personas con Discapacidad, Nueva York, 13 de diciembre. Disponible en http://www.un.org/spanish/disabilities/default. asp?id=497 Consulta: 24 de junio de 2017.

3 Organización de Naciones Unidas (ONU), 2006, Protocolo Facultativo de la Convención sobre los Derechos de las Personas con Discapacidad, Nueva York, 13 de diciembre. Disponible en http://www.un.org/spanish/ disabilities/default.asp?id=497 Consulta: 24 de junio de 2017.

4 Organización de Naciones Unidas (ONU), 2006, Asamblea General, A/RES/61/106, Sexagésimo primer período de sesiones, (13 de diciembre de 2006). Consulta: 24 de junio de 2017. Disponible en www.un.org/esa/ socdev/enable/documents/ares61106s.doc 
de los citados tratados supuso su incorporación al ordenamiento jurídico argentino; ya que la CN vigente, luego de su reforma de 1994, establece en su artículo 75, inciso 22 que, entre las atribuciones del Congreso, se encuentra la de «Aprobar o desechar tratados concluidos con las demás naciones y con las organizaciones internacionales y los concordatos con la Santa Sede $»^{5}$, seguidamente, agrega que: «Los tratados y concordatos tienen jerarquía superior a las leyes» ${ }^{5}$, de lo que se deduce que, ante un conflicto entre una ley nacional y un tratado internacional con jerarquía supralegal, debe prevalecer este último.

Partiendo de este antecedente normativo, debemos mencionar que la CRDP, en su artículo 23, punto 2, dispone que: «Los Estados Partes prestarán la asistencia apropiada a las personas con discapacidad para el desempeño de sus responsabilidades en la crianza de los hijos $\rangle^{2}$. Como se ve, el articulado obliga a Argentina, en tanto país signatario, a respetar y asegurar el derecho al hogar y a la familia. En este punto, se debe observar que la CRDP impone a los Estados Partes el paradigma social de la discapacidad, es decir, aquel que afirma que la discapacidad no surge por una deficiencia que porta un cuerpo, sino por las barreras sociales que se verifican en una sociedad que no considera, o lo hace de forma insuficiente, a las personas con discapacidad y las excluye de las posibilidades de una vida en común. (Palacios. 2008) Dicha afirmación encuentra su fundamento en el artículo 12 de la $\mathrm{CRDP}^{6}$, el cual reconoce la capacidad y la personalidad jurídica de las personas con discapacidad, además de establecer la igualdad de condiciones en todos los aspectos de la vida, incluido el social. A nivel continental, y en el mismo tenor, se expresa la Convención Interamericana para la Eliminación de Todas las Formas de Discriminación contra las Personas con Discapacidad ${ }^{7}$ (en adelante CIADDIS) — ratificada por Argentina por

\footnotetext{
5 Constitución de la Nación Argentina. 1994. Buenos Aires. Editorial Ministerio de Justicia y Derechos Humanos de la Nación.

6 Artículo 12 de la Convención sobre los Derechos de las Personas con Discapacidad: «1.Los Estados Partes reafirman que las personas con discapacidad tienen derecho en todas partes al reconocimiento de su personalidad jurídica. 2. Los Estados Partes reconocerán que las personas con discapacidad tienen capacidad jurídica en igualdad de condiciones con las demás en todos los aspectos de la vida».

7 Organización de los Estados Americanos (OEA), 1999, Convención Interamericana para la Eliminación de Todas las Formas de Discriminación contra las Personas con Discapacidad, Guatemala, 6 de julio. Disponible en http://www.oas.org/juridico/spanish/tratados/a-65.html Consulta: 24 de junio de 2017.
} 
medio de la ley $25.280^{8}$ - ya que el Diagnóstico Regional sobre el Ejercicio de la Capacidad Jurídica de las Personas con Discapacidad publicado en el año 2015, desarrollado por la Secretaría Técnica del Comité para la Eliminación de de Todas las Formas de Discriminación contra las Personas con Discapacidad, dependiente de la Organización de Estados Americanos (en adelante OEA), sostiene que: «Para la aplicación plena y efectiva de la CIADDIS es fundamental que en las legislaciones nacionales se aborde la discapacidad desde el modelo social, migrando desde el modelo médico-rehabilitador, lo que implica abandonar las definiciones de carácter médico únicamente, articuladas según el tipo de deficiencia, y reconocer que las personas con discapacidad aportan a la sociedad en la misma medida que las personas sin discapacidad»

Por otro lado, a nivel nacional, las personas con discapacidad cuentan con la ley 24.901, la cual contempla una serie de prestaciones básicas de atención integral, además de definir en su artículo 9, el concepto legal de persona con discapacidad: «Toda aquella que padezca una alteración funcional permanente o prolongada, motora, sensorial o mental, que en relación a su edad y medio social implique desventajas considerables en su integración familiar, social, educacional o laboral».

En cuanto a la discapacidad mental en particular, debemos tener presente, además, a la ley $26.657^{9}$ relativa a la protección de la Salud Mental, en cuyo artículo 1 se garantiza: «El pleno goce de los derechos humanos de aquellas personas con padecimiento mental que se encuentran en el territorio nacional, reconocidos en los instrumentos internacionales de derechos humanos, con jerarquía constitucional, sin perjuicio de las regulaciones más beneficiosas que para la protección de estos derechos puedan establecer las provincias y la Ciudad Autónoma de Buenos Aires».

Desde el punto de vista estadístico, la Encuesta Nacional de Personas con Discapacidad, 2002-2003, (ENDI), Complementaria del Censo 2001, realizada

\footnotetext{
8 Congreso de la Nación, 2000, Ley 25.280, Buenos Aires, Argentina, 6 de julio. Disponible en http://servicios. infoleg.gob.ar/infolegInternet/anexos/60000-64999/63893/norma.htm Consulta: 24 de junio de 2017.

9 Congreso de la Nación, 2010, Ley 26.657, Ley Nacional de Salud Mental, Buenos Aires, Argentina, 25 de noviembre. Disponible en http://servicios.infoleg.gob.ar/infolegInternet/anexos/175000-179999/175977/ norma.htm Consulta: 25 de junio de 2017.
} 
por el INDEC, estima que, en Argentina, el 7.1\% de la población lo componen personas con discapacidad, y que además, el $20.6 \%$ de los hogares argentinos cuenta con al menos una persona con discapacidad ${ }^{10}$. En el mismo sentido, el Censo Nacional de Población, Hogares y Viviendas del año 2010, concluye que el porcentaje de población que presenta algún tipo de dificultad o limitación permanente (física y/o mental) es de $12,9 \%$ de las personas que habitan en viviendas particulares, representado en cifras sería 5.114.190 ${ }^{11}$. Son datos que demuestran que la discapacidad engloba una importante fracción poblacional del país y que, precisamente por ello, debe ser protegida.

Dentro del ámbito jurisprudencial, es menester señalar la postura que ha adoptado la Corte Suprema de Justicia de la Nación (en adelante CSJN) en relación al derecho a la maternidad de las mujeres que sufren algún tipo de discapacidad mental. Para ello, debemos hacer alusión al fallo caratulado: "I., J. M. s/ protección especial"12, emitido el 6 de junio de 2016, el cual es histórico, debido a que es la primera vez que, el máximo tribunal argentino, se expide sobre la citada temática. En él, la CSJN dictaminó la restitución de un hijo menor de edad, que previamente había sido puesto en situación de adoptabilidad, a su madre biológica con discapacidad mental. La sentencia, que comparte los fundamentos expuestos en el dictamen de la Procuración General de la Nación ${ }^{13}$ de fecha 4 de mayo de 2016, deja al descubierto las falencias e incumplimientos que el país viene cometiendo respecto a este colectivo de personas. Ésta coyuntura, como se analizará más adelante, radica en la falta de armonización existente entre la legislación nacional y los preceptos establecidos por la CRDP; además de la

10 Encuesta Nacional de Personas con Discapacidad (ENDI) 2002-2003, Argentina, INDEC: Instituto Nacional de Estadística y Censos de la República Argentina. Disponible en: http://www.indec.gov.ar/micro sitios/webcenso/ENDI_NUEVA/ampliada_index_total.asp?mode=01 Consulta: 25 de junio de 2017.

11 Censo Nacional de Población, Hogares y Viviendas 2010, Argentina, INDEC: Instituto Nacional de Estadística y Censos de la República Argentina. Disponible en: http://www.indec.gov.ar/ftp/cuadros/sociedad/ PDLP 10 14.pdf Consulta: 25 de junio de 2017.

12 Corte Suprema de Justicia de la Nación, “I., J. M. s/ protección especial” sentencia del 6 de junio de 2016, fallos 339:795, Disponible en: https://www.csjn.gov.ar/ Consulta: 25 de junio de 2017. http://sjconsulta.csjn. gov.ar/sjconsulta/documentos/verDocumentoByIdLinksJSP.html?idDocumento=7311912

13 Procuración General de la Nación, “I., J. M. s/ protección especial”, dictamen del 4 de mayo de 2016, fallos 339:795, Disponible en: https:/www.csjn.gov.ar/ Consulta: 25 de junio de 2017. http://sjconsulta.csjn.gov.ar/ sjconsulta/documentos/verDocumentoById.html?idDocumento $=7311911$ 
reticencia de los órganos judiciales a hacer prevalecer la CRDP.

Presentado, a modo introductorio, el plexo normativo específico de la materia, procederemos a estudiar sus alcances e implicancias, como así también algunos fallos recientes relativos a la problemática, y las observaciones que la Organización de las Naciones Unidas (en adelante ONU), ha efectuado a Argentina. En las páginas siguientes, buscaremos exponer la situación del derecho a la maternidad de las mujeres con discapacidad mental en el Estado argentino, además de determinar si éste, se encuentra cumpliendo, satisfactoriamente, sus compromisos internacionales para asegurar el mencionado derecho.

\section{La igualdad ante la ley: principal motivo de preocupación para la ONU}

El Comité sobre los Derechos de las Personas con Discapacidad de la ONU, señaló, en sus Observaciones finales sobre el informe inicial de Argentina ${ }^{14}$, aprobadas por el Comité en su octavo período de sesiones del 17 al 28 de septiembre de 2012 -último informe del Comité sobre Argentina hasta la fecha-, entre los principales motivos de preocupación, la falta de igualdad ante la ley que sufren las personas con discapacidad. Esto se debe al modelo sustitutivo de la voluntad de la persona, sobre el cual se basa la legislación argentina. Aquí se produce una colisión de derechos entre, la CRDP, que reconoce plenamente la capacidad jurídica de las personas con discapacidad en su artículo 12, reivindicándolas como sujetos de derecho, y el Código Civil Argentino, que en su título XIII contempla la figura legal de la curatela para los incapaces mayores de edad, en este sentido, el Comité: "Lamenta que el representante legal de una mujer con discapacidad bajo tutela pueda otorgar el consentimiento a un aborto no punible en nombre de la mujer con discapacidad». Respecto al derecho a la integridad personal que

\footnotetext{
14 Organización de Naciones Unidas (ONU) 2012. Observaciones finales sobre el informe inicial de Argentina, aprobadas por el Comité en su octavo período de sesiones. (17 a 28 de septiembre de 2012). Consulta: 25 de junio de 2017. Disponible en: http://docstore.ohchr.org/SelfServices/FilesHandler.ashx?enc=6QkG1d\%2FPP RiCAqhKb7yhspZQ2sppBOANJSxHHwrsEJaYmnlvM3jA08AJH2x7hoUTgh3174tt8\%2FqvOaLf8uHB4IloI qs87ffYYE4AhvtQvB\%2B2u\%2BONKQuePZFm\%2BRnNkrXO
} 
deben gozar todas las mujeres con discapacidad, consagrado en el artículo 17 de la CRDP, el Comité manifiesta su preocupación ante la existencia, en el país, de prácticas de esterilización de personas con discapacidad sin su consentimiento libre e informado. Por lo que recomienda a Argentina, que «Tome medidas para ofrecer los apoyos necesarios a las mujeres sometidas a un régimen de tutela o curatela para que sean ellas mismas las que den su consentimiento informado para acceder a la práctica del aborto no punible o esterilización».

Otra de las pautas fundamentales que dispone la CRDP, para asegurar el derecho a la maternidad de las mujeres con discapacidad, es el respeto al hogar y a la familia, contemplado en el artículo 23: «Los Estados Partes tomarán medidas efectivas y pertinentes para poner fin a la discriminación contra las personas con discapacidad en todas las cuestiones relacionadas con el matrimonio, la familia, la paternidad y las relaciones personales, y lograr que las personas con discapacidad estén en igualdad de condiciones con las demás». El Comité de la ONU determinó que, en Argentina, existe una falta de reconocimiento al derecho que tienen las personas con discapacidad a formar una familia, en especial, de aquellas que han sido declaradas insanas o inhabilitadas, instando al Estado a que «Ofrezca los apoyos necesarios para el ejercicio de la maternidad y paternidad de las personas con discapacidad que lo requieran».

Como se observa, son numerosos los aspectos que el Estado argentino debe corregir para lograr una adecuada armonización entre el modelo jurídico que propone la CRDP y lo que establece el derecho interno; evidenciando una severa precariedad en la legislación que debe ser superada para poder brindar una protección eficaz a las mujeres con discapacidad mental. En este orden de ideas, analizaremos a continuación la jurisprudencia más reciente al respecto, para demostrar la resistencia que existe, en la mayoría de los agentes judiciales, para llevar a cabo medidas tendientes a evitar la discrecionalidad judicial ${ }^{15}$, la cual, muchas veces, restringe la capacidad jurídica de las personas con discapacidad.

15 Al respecto, Eduardo López Betancourt sostiene que: "Se entiende a la discrecionalidad judicial como la libertad o el arbitrio con que actúan los jueces, cuando el contenido normativo no les proporciona criterios exhaustivos que les permitan enunciar una solución única, y su decisión consiste en una elección entre diferentes opciones". 


\section{Postura jurisprudencial de la Corte Suprema de Justicia de la Nación: el fallo "I., J. M. s/protección especial"}

Con el objetivo de examinar los perjuicios que generan los operadores judiciales, al privilegiar su discrecionalidad judicial, en vez de atenerse a los tratados internacionales — según lo determina el control de constitucionalidad y el control de convencionalidad - se analizará a continuación el fallo: "I., J. M. s/ protección especial" emitido por la CSJN en el año 2016, el cual se ha convertido en un importante precedente para proteger, en el futuro, el derecho a ser madre. Además, el fallo constituye un ejemplo paradigmático para describir las dificultades que experimentan las mujeres con discapacidad mental al momento de pretender materializar su derecho a la maternidad. Del mismo modo, se expondrán los hechos y argumentos sostenidos, tanto por el juzgado de primera instancia como por la Cámara Nacional de Apelaciones en lo Civil intervinientes, cuyas resoluciones motivaron la sentencia de la CSJN.

\subsection{Antecedentes del fallo de la CSJN}

El día 6 de abril del año 2012, C.M.I., una mujer mayor de edad que padece discapacidad mental, específicamente: retraso madurativo, y en situación de pobreza, dio a luz a un niño - al que llamaremos J.M.I., a los fines de proteger su identidad- en el Hospital Materno Infantil Ramón Sardá, ubicado en la Ciudad de Buenos Aires (en adelante CABA). Debido a la información remitida por el sanatorio, actuó de oficio el Juzgado Nacional de Primera Instancia en lo Civil $\mathrm{N}^{\mathrm{o}}$ 10, iniciando el proceso caratulado "C., M. L. s/ insania".

El informe socioambiental, efectuado por la Licenciada en Trabajo Social del juzgado, resolvió que el menor se hallaba en una grave situación de vulnerabilidad, por lo que intervino el Ministerio Pupilar, quien dispuso un trámite de protección especial sobre el menor. De ésta manera, una vez que el niño estuvo en condiciones de ser externado, el juzgado ordenó su derivación del Hospital, al Hogar Querubines, en el que permaneció desde el 7 de julio de 2012, hasta el 7 de 
junio de 2016, fecha en que la CSJN ordenó que sea restituido a su madre. Aquí resulta necesario señalar el grave e irreparable menoscabo sufrido por el niño -ya que el tiempo es una magnitud física de impracticable restitución-, que durante cuatro años fue privado de su derecho a ser criado por su madre. Durante la citada fracción temporal, se produjeron una serie de incumplimientos de los principales tratados internacionales en la materia, tales como la Convención sobre los Derechos del $\mathrm{Niño}^{16}$ (en adelante $\mathrm{CDN}$ ), así podemos mencionar su artículo 7, el cual reconoce al niño el derecho a conocer a sus padres y a ser cuidado por ellos; el artículo 9, que obliga a los Estados signatarios a velar porque el niño no sea separado de sus padres contra la voluntad de éstos; el artículo 18, por el que los Estados se obligan a prestar la asistencia adecuada a los padres para garantizar y promover los derechos de la CDN; por otro lado, se observa el incumplimiento del punto 2 del artículo 23 de la CRDP².

La Escuela de Educación Especial y Formación Laboral N³6, donde concurre la progenitora, advirtió la necesidad de que el niño y la madre debían alojarse juntos. Ante tal observación, el juzgado dispuso una evaluación psiquiátrica de la madre, aconsejada por la psicóloga del Hospital Sardá; en virtud de ello, se requirió al Director del Hospital Neuropsiquiátrico Braulio Moyano, que formara una junta evaluadora a los fines de determinar si la madre se hallaba en condiciones de ejercer su capacidad maternal en forma independiente. En diciembre de 2012, la junta médica concluyó que: «Se encuentra en condiciones de convivir y realizar el cuidado de su hijo, bajo control y supervisión periódica».

Paralelamente, en octubre de 2012 C.M.I., por representación de su abogada, la Dra. Graciela Fijtman, propuso a la Dirección General de la Niñez de CABA, un proyecto que contemplaba el alojamiento de madre e hijo en el Hogar Nazareth. Tal iniciativa fue desechada por el Gobierno de la Ciudad de Buenos Aires, arguyendo que el mismo no cuenta con hogares que se adapten a tal objetivo. Aquí se aprecia, con toda claridad, la insuficiencia del Estado argentino para brindar apoyos adecuados a las mujeres con discapacidad mental, en claro incumplimiento del artículo 6, punto 1 (de las Mujeres con Discapacidad) de

16 Organización de Naciones Unidas (ONU), 1989, Convención sobre los Derechos del Niño, Nueva York, 20 de noviembre. Disponible en http://www.ohchr.org/SP/ProfessionalInterest/Pages/CRC.aspx Consulta: 25 de junio de 2017. 
la CRDP, el cual establece que los Estados Partes: «Adoptarán medidas para asegurar que puedan disfrutar plenamente y en igualdad de condiciones de todos los derechos humanos y libertades fundamentales», y el artículo 25, apartado 2, de la Declaración Universal de Derechos Humanos (en adelante DUDH): «La maternidad y la infancia tienen derecho a cuidados y asistencia especiales» ${ }^{17}$, la DUDH goza, desde la reforma de la CN en 1994, de jerarquía constitucional, así lo dispone el artículo 75, inciso 22.

Ante la negativa del Poder Ejecutivo de CABA, el Ministerio Pupilar lo instó a adoptar las medidas administrativas necesarias para obtener una solución apropiada para hacer efectivo el alojamiento de madre e hijo. Las falencias burocráticas hicieron que recién en junio de 2013 —ocho meses después de solicitado el sistema de apoyos-, la Dirección de la Niñez de CABA ofreciera un hogar - el Hogar 26 de Julio-, pero enmarcado dentro de un régimen de visitas. Sin embargo, dicha institución no está orientada a brindar apoyos a mujeres con discapacidad, sino a mujeres en estado de vulnerabilidad, además, se halla a una gran distancia de la Escuela especial donde estudia C.M.I., como así también de su domicilio. Por lo que la iniciativa fracasó.

\subsection{Sentencia del Juzgado de Primera Instancia}

En este punto del proceso, discrecionalmente y de manera arbitraria, el juzgado interviniente no valoró el informe de la junta evaluadora del Hospital Moyano, el cual determinó la efectiva capacidad de C.M.I, para ejercer la maternidad, aunque remarcando la necesidad de una supervisión periódica. En vez de ajustarse a los estándares internacionales que obliga al Estado argentino a brindar una red de apoyos para el efectivo ejercicio de la maternidad, el juzgado de primera instancia concluyó que C.M.I. demostró una conducta errática e inconstante para vincularse con su hijo, debido al fracaso del régimen de visitas dispuesto en el

17 Organización de Naciones Unidas (ONU), 1948, Declaración Universal de los Derechos Humanos, Paris, 10 de diciembre. Disponible en http://www.un.org/es/universal-declaration-human-rights/ Consulta: 25 de junio de 2017. 
Hogar 26 de Julio, atribuyéndolo a sus limitaciones madurativas. En realidad, la iniciativa no prosperó, por otras causas, como la distancia física existente entre el domicilio de la progenitora y el mencionado hogar, además de no ser un establecimiento orientado a la maternidad, sino a la protección de mujeres en estado de vulnerabilidad.

El fallido plan de apoyos ofrecido por la Dirección de la Niñez de CABA, debe atribuirse, no a C.M.I., sino a la desidia estatal. En definitiva, CABA no brindó la debida asistencia a una madre con discapacidad mental que deseaba ejercer su maternidad, con los mismos derechos y obligaciones que las demás mujeres, discriminándola y privándola de su derecho a ser madre.

Lejos de brindar apoyos y soluciones concordantes con los instrumentos internacionales, para que C.M.I. pudiera cumplir su rol de madre, el juzgado la intimó para que en un plazo tan exiguo, de cinco días, presentase, nada más ni nada menos, que un proyecto de vida sobre su hijo. C.M.I, no pudo cumplir con tales tiempos procesales, por lo que el juzgado sentenció: «Ante su silencio se resuelve - teniendo en cuenta las limitaciones madurativas de C.M.I, en hacerse cargo del niño y no contar con los debidos apoyos ni un marco familiar continente- que J.M.I, tiene derecho a una existencia sana en un hogar y a no estar institucionalizado de por vida, de manera tal que los padecimientos de base de la madre, quien no pudo elaborar un proyecto vital, no dejan otra opción que decretar el estado de abandono y adaptabilidad del niño». El razonamiento de la sentencia es claro: debido a su discapacidad, es inhábil para ejercer la maternidad. Llamativa es la expresión «existencia sana», como así también el término «padecimientos de base», utilizados para referirse a la discapacidad mental de C.M.I, como si ésta constituyera un aspecto desfavorable de su persona y que, simplemente por ello, se es lícito separar al menor de su madre, para que pueda llevar una vida sana, alejado de su progenitora, depositando una carga negativa sobre la discapacidad. En relación a lo aludido, es oportuno comentar que CABA sancionó, el día 23 de abril de año 1998, la ley $\mathrm{N}^{0}$ 22, en cuyo artículo 1 se dispuso que: «Utilícese, en el ámbito del Gobierno de la Ciudad Autónoma de Buenos Aires, la denominación "Personas con discapacidad", para todas aquellas que tuvieren algún tipo de discapacidad» ${ }^{18}$.

18 Legislatura de la Ciudad Autónoma de Buenos Aires, 1998, Ley No 22, Buenos Aires, Argentina, 23 de abril. 


\subsection{Rechazo al recurso de apelación por parte de la Cámara Nacional de Apelaciones en lo Civil.}

Contra la sentencia de primera instancia, C.M.I. interpuso recurso de apelación, por lo que intervino la Sala B de la Cámara Nacional de Apelaciones en lo Civil, la cual, luego de escuchar in situ el testimonio de la progenitora, la instó a que solicite un plan de apoyos.

Una vez presentado, el plan fue descartado por la Cámara, quien calificó de insuficientes las propuestas diseñadas, tanto por C.M.I, como por los órganos estatales, rechazando la apelación y confirmando la sentencia de primera instancia. La Cámara argumentó, en su decisorio, que C.M.I, no ha podido sostener su deseo de ser madre, además de constatar el abandono material y moral del menor. En vistas de tal circunstancia, y considerando el interés superior del niño, ordenó que éste sea puesto en situación de adoptabilidad. Rechazado el recurso de apelación por la Cámara, la defensa interpuso recurso de queja ante la CSJN, valiéndose de la ley 48, que en su artículo 14, punto 1, establece que solo podrá apelarse a la CSJN, las sentencias definitivas pronunciadas por los tribunales superiores en los casos siguientes: "Cuando en el pleito se haya puesto en cuestión la validez de un Tratado, de una ley del Congreso, o de una autoridad ejercida en nombre de la Nación y la decisión haya sido contra su validez» ${ }^{19}$.

\section{4 Sentencia de la CSJN}

E1 7 de junio de 2016, la CSJN hizo lugar a la queja, disponiendo: «El reintegro de J.M.I. a su madre, con un proceso previo de adaptación, debiendo implementarse con la premura del caso». La CSJN, argumentando razones de tiempo, compartió los fundamentos del Dictamen elaborado por el Ministerio Público Fiscal (en adelante MPF). El MPF, consideró que la decisión de la Cámara: «Pone en tela de juicio la inteligencia y aplicación de los tratados sobre los derechos de los niños

Disponible en https://www.fiscalias.gob.ar/wp-content/uploads/prev/caba-ley-22-personas-con-necesidadesespeciales.pdf Consulta: 25 de junio de 2017.

19 Congreso Federal, 1863, Ley No 48, Buenos Aires, Argentina, 25 de agosto. Disponible http://servicios. infoleg.gob.ar/infolegInternet/anexos/115000-119999/116296/texact.htm Consulta: 25 de junio de 2017. 
y de las personas con discapacidad, y su directa incidencia sobre la aplicación de reglas de derecho de familia que han de ser entendidas a la luz de los principios y previsiones de aquellos convenios».

\subsection{El interés superior del niño}

Como se ha mencionado, en el fallo "I., J. M. s/ protección especial", la Cámara dispuso la adoptabilidad del menor, amparándose en el interés superior del niño; sin embargo, es preciso clarificar este concepto que, muchas veces, puede resultar difuso. La Cámara, entendió que consistía en alejarlo de su madre con discapacidad para colocarlo en situación de adoptabilidad, ya que tenía derecho a una existencia sana, y que los padecimientos mentales de la madre no tenían por qué malograr su desarrollo como individuo, obligándolo a estar institucionalizado, a la vez que constaban su abandono moral y material.

La CDN, en su artículo 3, expresa que: «En todas las medidas concernientes a los niños que tomen las instituciones públicas o privadas de bienestar social, los tribunales, las autoridades administrativas o los órganos legislativos, una consideración primordial a que se atenderá será el interés superior del niño». Dejando en claro que, siempre, debe prevalecer este bien jurídico tutelado. Pero a los fines de hallar una definición, debemos atenernos a la Observación general $\mathrm{N}^{\circ} 14$ del año 2013, que elaboró el Comité de Derechos del Niño de la ONU, en la que se afirma que: «El objetivo del concepto de interés superior del niño es garantizar el disfrute pleno y efectivo de todos los derechos reconocidos por la Convención y el desarrollo holístico del niño ${ }^{20}$, de lo que se deduce que, una sentencia judicial, no puede prevalecer por sobre la obligación de respetar todos los derechos del niño enunciados en la CDN. Teniendo en cuenta estas consideraciones, el dictamen del MPF concluyó que: «La invocación al interés superior del niño para ser colocado en situación de adoptabilidad, sin la correspondiente evaluación del perjuicio que le ocasionará ser criado por una posible familia adoptiva, lejos de

20 Organización de Naciones Unidas (ONU) 2013. Observación general Nº 14 sobre el derecho del niño a que su interés superior sea una consideración primordial, aprobada por el Comité en su $62^{\circ}$ período de sesiones. (14 de enero a 1 de febrero de 2013). Consulta: 25 de junio de 2017. Disponible en: http://www.unicef.cl/web/ informes/derechos_nino/14.pdf 
su madre, de su hermano menor quién sí convive con ella (mientras se tramitaba el expediente, C.M.I, tuvo otro hijo), y de la restante familia materna, aún con las limitaciones de éstos, es una clara demostración de la ausencia de una debida fundamentación». Por lo que, finalmente, la sentencia de la alzada fue revocada.

\subsection{EI fallo "G., M.G, s/protección de persona" y su valioso aporte para interpretar el interés superior del niño}

En la jurisprudencia de la CSJN existen precedentes que pueden resultar útiles para establecer ciertas reglas interpretativas en relación al interés superior del niño. Así, desarrollaremos, sucintamente, el fallo de la CSJN caratulado: "G., M.G, s/protección de persona" 21 , emitido el 16 de septiembre de 2008, el cual presenta similitudes con “I., J. M. s/ protección especial”. La causa se inició por una protección de persona solicitada por el Defensor de Menores de primera instancia, en virtud de un informe remitido por el Hospital Santojanni —ubicado en $\mathrm{CABA}$-, del día 5 de septiembre de 2005, en el que se informaba el ingreso de un menor de sexo masculino de seis meses de edad, con un grave cuadro de bronquiolitis. La profesional médica actuante, declaró que el niño fue ingresado por una persona que refirió haber estado al cuidado del mismo, luego, se apersonó una joven que dijo ser su madre, ésta manifestó una conducta violenta y obstructiva para con el accionar médico y para con el niño, y quiso retirarlo inmediatamente. Luego, la joven se retiró del nosocomio y no volvió a aparecer; por lo que el menor fue ingresado al Programa Amas Externas del Consejo Nacional de la Niñez, Adolescencia y Familia, el cual consistía en convocar a familias para que brinden, de manera transitoria, un hogar a niños en situación de abandono.

Se dio curso a una serie de evaluaciones e informes para determinar si los abuelos maternos tenían la aptitud para ser guardadores del niño. El resultado fue negativo, por lo que el menor fue puesto bajo la guarda provisoria de una familia vecina. Una vez que se produjo ésta entrega, la familia biológica se desinteresó

21 Corte Suprema de Justicia de la Nación, "G., M.G, s/protección de persona" sentencia del 16 de abril de 2008, fallos 331:2047, Disponible en: https://www.csjn.gov.ar/ Consulta: 25 de junio de 2017. http://sjconsulta. csjn.gov.ar/sjconsulta/documentos/verUnicoDocumentoLink.html?idAnalisis=653101 
del menor - tanto la madre como la abuela se mudaron sin dejar datos de sus nuevos domicilios-, por lo que el Juzgado Nacional de Primera Instancia en lo Civil N ${ }^{\circ} 106$, dictó el abandono moral y material del niño, declarándolo en estado de adoptabilidad. La familia que le brindó la guarda provisoria interpuso recurso extraordinario ante la Sala A de la Cámara Nacional de Apelaciones en lo Civil, por entender que, atentos al interés superior del niño, lo mejor sería que ellos mismos sean los adoptantes, en lugar de volver a generar un cambio de hogar que, con toda seguridad, traería aparejado un trauma al niño. La Cámara confirmó la sentencia de primera instancia, ya que la familia que proveyó el hogar transitorio, no se hallaba inscripta en el Registro Único de Aspirantes a Guarda con Fines Adoptivos.

Vía recurso de queja, el expediente se elevó a la CSJN, quien se expidió a través del fallo "G., M.G, s/protección de persona”. En su considerando $7^{\circ}$, la ministra Dra. Carmen Argibay, consideró que «La regla del artículo 3.1 de la Convención sobre los Derechos del Niño, que ordena sobreponer el interés del niño a cualesquiera otras consideraciones, tiene - al menos en el plano de la función judicial donde se dirimen controversias-, el efecto de separar conceptualmente aquel interés del niño como sujeto de derecho de los intereses de otros sujetos individuales o colectivos. En la medida que todo cambio implica un «trauma» para el niño, debe demostrarse que no llevarlo a cabo le causaría un daño mayor o más grave $»^{24}$. Precisamente, la exigencia señalada por la Dra. Argibay, no fue cumplida en el fallo "I., J. M. s/ protección especial", ni por el juzgado ni por la Cámara, al no adecuarse a las reglas hermenéuticas establecidas por la CSJN; ya que en ningún punto del fallo se probó, cabalmente, que el hecho de permanecer con su madre le ocasionaría un daño más grave que el de ser puesto en adopción a una familia desconocida para él.

En “I., J. M. s/ protección especial”, la CSJN sostuvo que, para que pueda otorgarse el estado de adoptabilidad, se debe haber constatado, previamente, que la permanencia del menor con su familia biológica implicaría un agravio al mejor interés del niño, lo cual debe comprobarse a través de un riguroso estudio multidisciplinario. Así, se deben llevar a cabo estudios psiquiátricos y psicodiagnósticos de los niños y su progenitora, haciendo énfasis en las características de la relación materno-filial, y a la aptitud de la madre para el ejercicio adecuado 
de la función materna, como así también la elaboración de un informe ambiental.

De modo que la CSJN adopta la postura de que, antes de colocar en situación de adoptabilidad a un menor, hijo de madre con discapacidad mental, se deben haber desplegado medidas de protección y de apoyo y que, una vez fracasadas, podrán habilitarse otras formas de intervención.

En contrapartida a este marco legal, tanto el juzgado de primera instancia como la Cámara de Apelaciones en lo Civil, en el fallo "I., J. M. s/ protección especial", ignoraron tales dispositivos, por lo que nunca pudo ponerse a prueba la capacidad maternal de C.M.I; ya que durante los cuatro años que duró el proceso, jamás madre e hijo convivieron -el niño ha vivido institucionalizado, prácticamente, desde su nacimiento- lo que significa que a C.M.I, no se le otorgó la debida oportunidad de demostrar su capacidad como madre, incurriendo, tanto el juzgado como la Cámara, en un dogmatismo basado en prejuicios. Otro aspecto curioso, que debe destacarse, es el hecho de que C.M.I. dio a luz a otro hijo, que sí vive bajo el cuidado de ella, y sobre el cual no pesa ningún tipo de medida judicial. Esta coyuntura expone una contradicción jurídica preocupante, dado que si la justicia dictaminó su incapacidad para ejercer el rol materno, ¿cómo se explica que haya podido criar a otro niño, contemporáneamente al desarrollo del proceso judicial analizado? Tales hechos demuestran, en todo caso, que C.M.I, estuvo todo el tiempo en condiciones de desempeñar su maternidad.

Pese a que el fallo "I., J. M. s/ protección especial", consagra un precedente notable, dentro de la jurisprudencia argentina, para asegurar el derecho a la maternidad de las mujeres con discapacidad mental, existen otras sentencias recientes en las que este derecho ha sido negado. Tal es el caso del fallo "R., M. L. s/protección de personas" ${ }^{22}$.

22 Cámara de Apelaciones en lo Civil y Comercial de Salta, Sala Cuarta, "R., M. L. s/protección de personas" sentencia del 30 de enero de 2017, Expte. Nº8159-04, Disponible en: http://www.diariojudicial.com/ Consulta: 25 de junio de 2017. http://public.diariojudicial.com/documentos/000/072/492/000072492.pdf 


\section{Cuando la gravedad de la discapacidad mental impide el ejercicio del derecho a la maternidad}

El fallo "R., M. L. s/protección de personas", fue dictado por la Sala IV de la Cámara de Apelaciones en lo Civil y Comercial de la provincia de Salta, el 30 de enero del 2017. Los hechos que motivaron el fallo se basan en que, el Juzgado de $1^{\circ}$ Instancia en lo Civil de Personas y Familia, declaró el estado de adoptabilidad de una niña menor de edad, cuya madre presenta discapacidad mental. En este caso, a diferencia del retraso madurativo que poseía C.M.I, se trata de una patología mental más severa: psicosis crónica y esquizofrenia paranoide, además de recurrentes episodios de alcoholismo. Por lo que el informe médico del juzgado determinó su imposibilidad para ejercer el rol de madre. La Defensora Oficial Civil, interpuso recurso de apelación ante la Cámara, la cual confirmó la resolución apelada. La Cámara basó su decisión en que, a pesar que desde diciembre de 2012 se ha trabajado debidamente en la revinculación de la niña con su madre, no se alcanzaron resultados favorables; llegándose, incluso, a probarse episodios de descuido y maltrato hacia la menor por parte de la progenitora. Por lo que interpretó que debe privilegiarse el interés superior del niño. El fallo se fundamentó en la CDN, y en lo dispuesto en la normativa interna, ya que el nuevo Código Civil y Comercial argentino, vigente a partir del $1^{\circ}$ de agosto de 2015, en su artículo 607, inciso c), establece que la declaración judicial de la situación de adoptabilidad se dicta si, dentro del plazo máximo de 180 días no han dado resultado las medidas tendientes a que el niño permanezca con la familia de origen ${ }^{23}$. Dicho término, ha sido claramente superado, puesto que la Cámara sostuvo que: «No se trata solamente de la discapacidad de la madre sino también de su alcoholismo y conducta violenta que no han sido superados a lo largo de más de una década. No se comprende cuánto más debe esperarse para resolver la vulnerable situación de una niña que ha crecido dentro del seno de una familia "sustituta" bajo un sistema provisorio que no debió extenderse en el tiempo y que la llevó a crecer y desarrollarse sin la estabilidad, seguridad y contención necesarias para su edad».

23 Código Civil y Comercial de la Nación. 2015. Buenos Aires. Editorial Ministerio de Justicia y Derechos Humanos de la Nación. 
Del fallo "R., M. L. s/protección de personas" se extrae que, pese a que la CRDP reconoce la capacidad jurídica de las personas con discapacidad, también dispone en el artículo 23, punto 4, que los niños y las niñas no sean separados de sus padres contra su voluntad, salvo autoridad judicial fundada en el interés superior del niño. Tal es lo que se ha configurado en los autos analizados. Por lo que dependiendo de las particularidades del caso concreto, se puede asegurar el derecho a la maternidad de las mujeres con discapacidad mental (I., J. M. s/ protección especial,) mientras que en otros, es denegado (R., M. L. s/protección de personas). Asimismo, en la jurisprudencia hasta aquí estudiada, se aprecia la tensión existente entre el derecho a la maternidad de las mujeres con afecciones mentales, y los derechos del niño; demostrando que, en la justicia argentina, lograr la armonía entre ambos bienes jurídicos tutelados se vuelve una tarea compleja, principalmente, debido a la incertidumbre que genera determinar ¿Qué es lo mejor para el niño?

\section{Conclusión}

De lo expuesto, se concluye que la situación del derecho a la maternidad de las mujeres con discapacidad mental en Argentina es precaria e inestable. Básicamente, porque el Estado argentino no ha logrado aún una efectiva armonización de su legislación nacional, provincial y municipal con la CRDP. Existen inconsistencias que afectan las sentencias judiciales, al ignorar los principios hermenéuticos que surgen de los tratados internacionales vinculados a la temática, y de la propia jurisprudencia de la CSJN.

Por otro lado, los tribunales inferiores de primera instancia, y las Cámaras de Apelaciones en materia civil, se muestran reticentes a aceptar el igual reconocimiento de la persona con discapacidad ante la ley. En ese sentido, es necesario que se dé cumplimiento a los llamados «Ajustes razonables», es decir, «Aquellas modificaciones y adaptaciones necesarias y adecuadas que no impongan una carga desproporcionada o indebida, cuando se requieran en un caso particular, para garantizar a las personas con discapacidad el goce o ejercicio, 
en igualdad de condiciones con las demás, de todos los derechos humanos y libertades fundamentales». Es inadmisible que un Estado que ha ratificado la CRDP incumpla sus obligaciones, a tal punto, que haya permitido la separación de un niño de su madre con discapacidad mental, por un período de cuatro años, como se comprobó en el fallo "I., J. M. s/ protección especial".

La dilación de la justicia argentina en materia de causas relativas a la discapacidad mental de las madres, es alarmante. Dichos retrasos se deben, en gran medida, a la falta de recursos judiciales y administrativos simplificados para las mujeres con discapacidad mental, como así también, a los arraigados prejuicios, presentes aún en la justicia, porque ¿De qué otra manera puede explicarse la negación a desempeñar la maternidad de C.M.I.?, sin siquiera poner a prueba la capacidad de la progenitora, puesto que jamás se ordenó que madre e hijo convivieran juntos durante algún tiempo, a los fines de hacer efectivas las evaluaciones conducentes a determinar su aptitud materna. ¿Por qué fue necesario que el expediente llegase hasta la CSJN?, cuando los tribunales inferiores debieron, ya en primera instancia, reconocer el derecho de la madre, a la luz de lo estipulado en los tratados internacionales, obligando al Estado a diagramar un adecuado plan de apoyos ante su virtual vulnerabilidad.

Por todo lo dicho, se concluye que, para generar una mayor protección del derecho a la maternidad de las mujeres con discapacidad mental en Argentina, es necesario fortalecer la armonía entre la norma internacional y local, a la vez que urge capacitar a los operadores judiciales sobre la legislación pertinente.

\section{Bibliografía}

Cámara de Apelaciones en lo Civil y Comercial de Salta, Sala Cuarta, "R., M. L. s/protección de personas" sentencia del 30 de enero de 2017, Expte. No98159-04, Disponible en: http://www.diariojudicial. com/ Consulta: 25 de junio de 2017. http://public.diariojudicial. com/documentos/000/072/492/000072492.pdf 
Censo Nacional de Población, Hogares y Viviendas 2010, Argentina, INDEC: Instituto Nacional de Estadística y Censos de la República Argentina. Disponible en: http://www.indec.gov.ar/ftp/cuadros/ sociedad/PDLP 10 14.pdf Consulta: 25 de junio de 2017.

Código Civil y Comercial de la Nación. 2015. Buenos Aires. Editorial Ministerio de Justicia y Derechos Humanos de la Nación.

Congreso de la Nación, 2008, Ley 26.378, Buenos Aires, Argentina, 21 de mayo. Disponible en http://servicios.infoleg.gob.ar/infolegInternet/ anexos/140000-144999/141317/norma.htm Consulta: 24 de junio de 2017.

Congreso de la Nación, 2000, Ley 25.280, Buenos Aires, Argentina, 6 de julio. Disponible en http://servicios.infoleg.gob.ar/infolegInternet/ anexos/60000-64999/63893/norma.htm Consulta: 24 de junio de 2017.

Congreso de la Nación, 1997, Ley 24.091, Buenos Aires, Argentina, 5 de noviembre. Disponible en http://servicios.infoleg.gob.ar/ infolegInternet/anexos/45000-49999/47677/norma.htm Consulta: 25 de junio de 2017.

Congreso de la Nación, 2010, Ley 26.657, Ley Nacional de Salud Mental, Buenos Aires, Argentina, 25 de noviembre. Disponible en http://servicios.infoleg.gob.ar/infolegInternet/ anexos/175000-179999/175977/norma.htm Consulta: 25 de junio de 2017.

Congreso Federal, 1863, Ley $\mathrm{N}^{\circ}$ 48, Buenos Aires, Argentina, 25 de agosto. Disponible http://servicios.infoleg.gob.ar/infolegInternet/ anexos/115000-119999/116296/texact.htm Consulta: 25 de junio de 2017.

Constitución de la Nación Argentina. 1994. Buenos Aires. Editorial Ministerio de Justicia y Derechos Humanos de la Nación.

Corte Suprema de Justicia de la Nación, "I., J. M. s/ protección especial" sentencia del 6 de junio de 2016, fallos 339:795, Disponible en: https://www.csjn.gov.ar/ Consulta: 25 de junio de 2017.

http://sjconsulta.csjn.gov.ar/sjconsulta/documentos/ 
verDocumentoByIdLinksJSP.html?idDocumento $=7311912$

Corte Suprema de Justicia de la Nación, "G., M.G, s/protección de persona" sentencia del 16 de abril de 2008, fallos 331:2047, Disponible en: https://www.csjn.gov.ar/ Consulta: 25 de junio de 2017. http://sjconsulta.csjn.gov.ar/sjconsulta/documentos/ verUnicoDocumentoLink.html idAnalisis $=653101$

Encuesta Nacional de Personas con Discapacidad (ENDI) 2002-2003, Argentina, INDEC: Instituto Nacional de Estadística y Censos de la República Argentina. Disponible en: http://www.indec.gov.ar/ micro_sitios/webcenso/ENDI_NUEVA/ampliada_index total. asp?mode $=01$

Organización de Naciones Unidas (ONU), 2006, Convención sobre los Derechos de las Personas con Discapacidad, Nueva York, 13 de diciembre. Disponible en http://www.un.org/spanish/disabilities/ default.asp?id=497 Consulta: 24 de junio de 2017.

Organización de Naciones Unidas (ONU), 2006, Protocolo Facultativo de la Convención sobre los Derechos de las Personas con Discapacidad, Nueva York, 13 de diciembre. Disponible en http://www.un.org/ spanish/disabilities/default.asp?id=497 Consulta: 24 de junio de 2017.

Organización de Naciones Unidas (ONU), 2006, Asamblea General, A/RES/61/106, Sexagésimo primer período de sesiones, (13 de diciembre de 2006). Consulta: 24 de junio de 2017. Disponible en www.un.org/esa/socdev/enable/documents/ares61106s.doc

Organización de los Estados Americanos (OEA), 1999, Convención Interamericana para la Eliminación de Todas las Formas de Discriminación contra las Personas con Discapacidad, Guatemala, 6 de julio. Disponible en http://www.oas.org/juridico/spanish/ tratados/a-65.html Consulta: 24 de junio de 2017.

Organización de los Estados Americanos (OEA), Diagnóstico Regional sobre el Ejercicio de la Capacidad Jurídica de las Personas con Discapacidad, Secretaría Técnica de CEDDIS, Washington D.C. 2015. Disponible en: http://www.oas.org/es/sedi/ddse/documentos/ 
espa\%C3\%B1ol_diagnostico.pdf Consulta: 24 de junio de 2017.

Organización de Naciones Unidas (ONU) 2012. Observaciones finales sobre el informe inicial de Argentina, aprobadas por el Comité en su octavo período de sesiones. (17 a 28 de septiembre de 2012). Consulta: 25 de junio de 2017. Disponible en: http://docstore.ohchr. org/SelfServices/FilesHandler.ashx? enc $=6 \mathrm{QkG1d} \% 2 \mathrm{FPPRiCAqhK}$ b7yhspZQ2sppBOANJSxHHwrsEJaYmnlvM3jA08AJH2x7hoUTg h3174tt8\%2FqvOaLf8uHB4IloIqs87ffYYE4AhvtQvB\%2B2u\%2B ONKQuePZFm\%2BRnNkrXO

Organización de Naciones Unidas (ONU), 1989, Convención sobre los Derechos del Niño, Nueva York, 20 de noviembre. Disponible en http://www.ohchr.org/SP/Professionalinterest/Pages/CRC.aspx Consulta: 25 de junio de 2017.

Organización de Naciones Unidas (ONU), 1948, Declaración Universal de los Derechos Humanos, Paris, 10 de diciembre. Disponible en http:/www.un.org/es/universal-declaration-human-rights/ Consulta: 25 de junio de 2017.

Organización de Naciones Unidas (ONU) 2013. Observación general $\mathrm{N}^{\mathrm{o}} 14$ sobre el derecho del niño a que su interés superior sea una consideración primordial, aprobada por el Comité en su $62^{\circ}$ período de sesiones. (14 de enero a 1 de febrero de 2013). Consulta: 25 de junio de 2017. Disponible en: http:/www.unicef.cl/web/informes/ derechos_nino/14.pdf

Legislatura de la Ciudad Autónoma de Buenos Aires, 1998, Ley No 22, Buenos Aires, Argentina, 23 de abril. Disponible en https://www. fiscalias.gob.ar/wp-content/uploads/prev/caba-ley-22-personas-connecesidades-especiales.pdf Consulta: 25 de junio de 2017.

López Betancourt, E. (2013). Discrecionalidad Judicial. La Jornada

Guerrero. Julio de 2013, México. Disponible en http://www.lajornadaguerrero.com.mx/2013/07/13/index.php?section=0 pinion\&article $=002 \mathrm{a} 1 \mathrm{soc}$ Consulta: 25 de junio de 2017

Palacios, Agustina, El modelo social de la discapacidad: orígenes, caracterización y plasmación en la Convención Internacional sobre 
los Derechos de las Personas con Discapacidad, CERMI, Madrid, España, 2008.

Procuración General de la Nación, "I., J. M. s/ protección especial", dictamen del 4 de mayo de 2016, fallos 339:795, Disponible en: https://www.csjn.gov.ar/ Consulta: 25 de junio de 2017. http:// sjconsulta.csjn.gov.ar/sjconsulta/documentos/verDocumentoById. $\underline{\text { html?idDocumento }=7311911}$ 
